\title{
Origin and early development of the chicken adenohypophysis
}

\author{
Luisa Sánchez-Arrones ${ }^{1+}$, José L. Ferrán ${ }^{1}$, Matías Hidalgo-Sanchez ${ }^{2}$ and Luis Puelles ${ }^{1}$ * \\ ' Faculty of Medicine, Department of Human Anatomy, School of Medicine and IMIB (Instiuto Murciano de Investigación Biosanitaria), University of Murcia, \\ Murcia, Spain \\ ${ }^{2}$ Department of Cell Biology, Faculty of Science, University of Extremadura, Badajoz, Spain
}

\section{Edited by:}

Gonzalo Alvarez-Bolado, University of Heidelberg, Germany

Reviewed by:

Kenji Shimamura, Kumamoto University, Japan

Diego Echevarria, University of Miguel Hernandez (UMH-CSIC), Spain

\section{*Correspondence:}

Luis Puelles, Faculty of Medicine, Department of Human Anatomy,

School of Medicine and IMIB

(Instiuto Murciano de Investigación

Biosanitaria), University of Murcia,

Campus Espinardo s/n, Murcia

30071 MU, Spain

e-mail:puelles@um.es

\section{${ }^{\dagger}$ Present address:}

Luisa Sánchez-Arrones, Centro de Biología Molecular Severo Ochoa,

Consejo Superior de

Investigaciones

Científicas - Universidad Autónoma

de Madrid, Madrid, Spain
The adenohypophysis ( $A D H)$ is an important endocrine organ involved in the regulation of many physiological processes. The late morphogenesis of this organ at neural tube stages is well known: the epithelial ADH primordium is recognized as an invagination of the stomodeal roof (Rathke's pouch), whose walls later thicken and differentiate as the primordium becomes pediculated, and then fully separated from the stomodeum. The primordium attaches to the pial surface of the basal hypothalamus, next to the neurohypophyseal field ( $\mathrm{NH}$; future posterior pituitary), from which it was previously separated by migrating prechordal plate (pp) cells. Once the $\mathrm{NH}$ evaginates, the ADH surrounds it and jointly forms with it the pituitary gland. In contrast, little is known about the precise origin of the $\mathrm{ADH}$ precursors at neural plate stages and how the primordium reaches the stomodeum. For that reason, we produced in the chicken a specific ADH fate map at early neural plate stages, which was amplified with gene markers. By means of experiments labeling the mapped presumptive $A D H$, we were able to follow the initial anlage into its transformation into Rathke's pouch. The ADH origin was corroborated to be strictly extraneural, i.e., to lie at stage $\mathrm{HH} 4 / 5$ outside of the anterior neural plate (anp) within the pre-placodal field. The ADH primordium is fully segregated from the anterior neural border cells and the neighboring olfactory placodes both in terms of precursor cells and molecular profile from head fold stages onwards. The placode becomes visible as a molecularly characteristic ectodermal thickening from stage $\mathrm{HH} 10$ onwards. The onset of $\mathrm{ADH}$ genoarchitectonic regionalization into intermediate and anterior lobes occurs at closed neural tube stages.

Keywords: adenohypophysis, anterior pituitary, fate map, pre-placodal ectoderm, placodes, gene markers, Rathke's pouch

\section{INTRODUCTION}

The pituitary gland of vertebrates is a key regulator of the endocrine system, required for the maintenance of reproduction, growth, homeostasis and metabolism. It develops by apposition of two embryonic primordia: the posterior pituitary gland, or neurohypophysis (NH), which is a dock for release of the hypothalamic neurohormones vasopressin and oxytocin are into the bloodstream, and the anterior pituitary gland, or adenohypophysis $(\mathrm{ADH})$, which represents a major endocrine control organ (Herzog et al., 2004; Guner et al., 2008). The $\mathrm{NH}$ develops as a digitiform median evagination from the

\footnotetext{
Abbreviations: abb, alar basal boundary; anp, anterior neural plate; ANR, anterior neural ridge; bp, basal plate; $\mathrm{Di}$, diencephalon; dt, digestive tube; $\mathrm{ec}$, ectoderm; HN, Hensen's node; Hypoth, hypothalamus; Inf, infundibulum; $\mathrm{mb}$, midbrain; N, notochord; nf, neural fold; nh, neurohypophysis; och, optic chiasm; oe, oral ectoderm; olf, olfactory placode; os, optic stalk; ov, optic vesicle; Pall, pallium; pp, prechordal plate; ppr, preplacodal region; PS, primitive streak; Pt/Th, Pretectum/Thalamus; Rh, Rhombencephalon; $\mathrm{rm}$, retromamilar; rp, Rathke's pouch; SP, secondary prosencephalon; SPall, subpallium; Tel, telencephalon.
}

hypothalamic tuberal neuroepithelium, at the area known as "median eminence" (Cobos et al., 2001; Puelles and Rubenstein, 2003; Herzog et al., 2004).

The ADH origin is still under discussion, since different developmental scenarios have been conjectured in the light of fate-mapping experiments in diverse vertebrates. The controversy centers on whether the ADH origin is neural or non-neural. Various fate-mapping studies performed at neurula stages in zebrafish, frog, and chick embryos reported that the ADH arises at the rostral border of the neural plate (known as the "anterior neural ridge", ANR; Takor and Pearse, 1975; Couly and Le Douarin, 1985; Eagleson et al., 1986; Couly and Le Douarin, 1987; elAmraoui and Dubois, 1993; Dubois and Elamraoui, 1995; Whitlock and Westerfield, 2000; Whitlock et al., 2003; Herzog et al., 2004). Specifically, Couly and Le Douarin (1988) thought that this early neural ADH primordium was continuous with the presumptive hypothalamic NH primordium (possibly suggesting, but not reasoning out, an implicit answer to the question about why $\mathrm{ADH}$ and $\mathrm{NH}$ later come to be joined in the pituitary gland). 
In contrast, other experimental work done in mammals and birds suggested that the primary $\mathrm{ADH}$ domain is not neural and arises from a median placodal ectodermal domain placed in front of (outside) the ANR. For instance, Cobos et al. (2001) concluded that the avian ANR domain proper contains exclusively prospective telencephalic cells (never giving rise to $\mathrm{NH}$ or $\mathrm{ADH}$ cells when grafted selectively). The $\mathrm{ADH}$ primordium was labeled only when the ectoderm forming the outer non-neural slope of the ANR was included in the grafts. This distinction was not made by earlier authors reporting such experiments. These results implied that the non-neural ADH primordium is separated from the prospective tuberal $\mathrm{NH}$ by several interposed neural domains, such as the telencephalic preoptic area (later represented at the midline by the lamina terminalis) and the hypothalamic chiasmatic, retrochiasmatic and tuberal areas. Their subsequent meeting must be due to parallel morphogenetic changes in position of the $\mathrm{ADH}$ and $\mathrm{NH}$ primordia. These results about the strictly telencephalic character of the ANR neural plate domain were corroborated later by more recent fate maps of the chicken neural plate (Fernández-Garre et al., 2002; Sanchez-Arrones et al., 2009, 2012; Cajal et al., 2012, 2014); see also zebrafish and frog fate maps (Houart et al., 1998; Eagleson and Dempewolf, 2002).

Everybody in the field agrees that Rathke's pouch, a dorsal evagination of the stomodeal roof, represents the immature $\mathrm{ADH}$ later in development (Cobos et al., 2001; Rizzoti and LovellBadge, 2005). It is also widely accepted that the stomodeal roof is ectodermal in character, rather than endodermal, thus excluding the possibility of an endodermal origin of the ADH. Nevertheless, it was found that the foregut endoderm underlying the early ANR is required during the specification of both the anterior neural border and the ADH primordium (Withington et al., 2001; Sanchez-Arrones et al., 2012).

There is little information, though, about how the early $\mathrm{ADH}$ primordium, be it neural or non-neural, comes to occupy the position of Rathke's pouch under the hypothalamus. This suggests the need of a detailed fate map and morphogenetic follow-up at several early developmental stages, in order to understand more fully the early development of the anterior pituitary gland (Figure 7). In this essay we re-examined in detail the origin and subsequent changing position of the $\mathrm{ADH}$ epithelial plate with regard to neighboring tissues at various stages. To address this issue, we first examined the early $\mathrm{ADH}$ field by fate mapping at neural plate stages (HH4/5) and survival up to closed neural tube stages (HH12), using the chick embryo as a model system. These data showed that the $\mathrm{ADH}$ precursors are located within an area distant 260$290 \mu \mathrm{m}$ from the node in the median non-neural ectoderm rostral (one might rather say "dorsal", or "peripheral") to the ANR. This ADH primordium is a close neighbor of the rostral midline telencephalic domain (prospective subpallial cells; see Cobos et al., 2001; Sanchez-Arrones et al., 2009; Cajal et al., 2014); the prospective $\mathrm{ADH}$ ectoderm was thus again found to lie just outside the neural plate and quite distant from the prospective $\mathrm{NH}$. Moreover, the $\mathrm{ADH}$ primordium directly overlies the boundary between the extraembryonic hypoblast and the rostralmost foregut endoderm precursors (Kimura et al., 2006).

Table 1 | Measurements of the experimental cases, data taken at HH4/5.

\begin{tabular}{|c|c|c|c|c|c|c|}
\hline Case & $\begin{array}{c}\text { Stage at } \\
\text { transplantation }\end{array}$ & $\begin{array}{l}\text { Stage of } \\
\text { fixation }\end{array}$ & Angle & $\begin{array}{c}\text { Distance } \\
\text { from HN }(\mu \mathrm{m})\end{array}$ & $\begin{array}{c}\text { Diameter of } \\
\text { the graft or } \\
\text { injection }(\mu \mathrm{m})\end{array}$ & $\begin{array}{c}\text { Distance } \\
\quad(\mu \mathrm{m})\end{array}$ \\
\hline RPA-02 & $\mathrm{HH} 4$ & $\mathrm{HH} 11+$ & $0-5^{\circ}$ & 274 & 77.4 & 351.4 \\
\hline RPA-03 & $\mathrm{HH} 4$ & $\mathrm{HH} 10$ & $5-10^{\circ}$ & 268 & 60 & 328 \\
\hline RPA-05 & $\mathrm{HH} 4$ & $\mathrm{HH} 10+$ & $0-5^{\circ}$ & 262 & 113 & 375 \\
\hline RPA-25 & $\mathrm{HH} 4$ & $\mathrm{HH} 10+$ & $0-5^{\circ}$ & 280 & 65.5 & 345.5 \\
\hline RPA-27 & $\mathrm{HH} 4$ & $\mathrm{HH} 11+$ & $0-5^{\circ}$ & 260 & 48 & 308 \\
\hline RPA-81 & $\mathrm{HH} 4$ & $\mathrm{HH} 11$ & $0-5^{\circ}$ & 310 & 84 & 394 \\
\hline RPA-80 & $\mathrm{HH} 4$ & $\mathrm{HH} 10$ & $0-5^{\circ}$ & 245 & 150 & 395 \\
\hline RPA-08 & $\mathrm{HH} 4$ & $\mathrm{HH} 11$ & $0-5^{\circ}$ & 173 & 113 & 286 \\
\hline RPA-06 & $\mathrm{HH} 5$ & $\mathrm{HH} 12$ & $0-5^{\circ}$ & 280 & 37.5 & 317.5 \\
\hline RPA-22 & $\mathrm{HH} 4$ & $\mathrm{HH} 10$ & $0-5^{\circ}$ & 234 & 84 & 318 \\
\hline RPA-30 & $\mathrm{HH} 4$ & $\mathrm{HH} 12$ & $0-5^{\circ}$ & 217 & 56 & 273 \\
\hline RPA-09 & $\mathrm{HH} 4$ & $\mathrm{HH} 10$ & $5-10^{\circ}$ & 170 & 42.5 & 212.7 \\
\hline RPA-26 & $\mathrm{HH} 4+$ & $\mathrm{HH} 12$ & $0-5^{\circ}$ & & & \\
\hline RPA-10 & $\mathrm{HH} 4$ & $\mathrm{HH} 9+$ & $15-20^{\circ}$ & 333 & 61 & 394 \\
\hline RPA-12 & $\mathrm{HH} 4$ & $\mathrm{HH} 9$ & $0-5^{\circ}$ & 350 & 67 & 417 \\
\hline RPA-18 & $\mathrm{HH} 4$ & HH11 & $5-10^{\circ}$ & 384 & 56 & 440 \\
\hline RPA-84 & $\mathrm{HH} 4$ & $\mathrm{HH} 9+$ & $10-15^{\circ}$ & 333 & 45 & 378 \\
\hline RPA-88 & $\mathrm{HH} 4$ & $\mathrm{HH} 10$ & $20-40^{\circ}$ & 417 & 84 & 501 \\
\hline RPA-11 & $\mathrm{HH} 4+$ & $\mathrm{HH} 11+$ & $0-5^{\circ}$ & & & \\
\hline RPA-29 & $\mathrm{HH} 4$ & HH9 & $15-20^{\circ}$ & 213 & 58 & 271 \\
\hline RPA-20 & $\mathrm{HH} 4$ & $\mathrm{HH} 11$ & $15-20^{\circ}$ & 223 & 70 & 293 \\
\hline RPA-14 & $\mathrm{HH} 4$ & $\mathrm{HH} 11$ & $0-5^{\circ}$ & 186 & 64 & 250 \\
\hline RPA-87 & $\mathrm{HH} 4$ & $\mathrm{HH} 11$ & $10-25^{\circ}$ & 245 & 27 & 272 \\
\hline
\end{tabular}




\section{MATERIALS AND METHODS \\ FATE MAP OF THE ROSTRAL MIDLINE ECTODERM}

Fertilized chicken eggs were incubated at $38^{\circ} \mathrm{C}$ to reach the desired stage. Fate-mapping experiments (Tables 1, 2) were performed at stage HH4/5 (Hamburger and Hamilton, 1951), with focal injections (Selleck and Stern, 1991) of carbocyanine dyes DiI (1, 1' -dioctadecyl-3,3,3',3'-tetramethylindocarbocyanine perchlorate; Invitrogen, D282) and/or DiO (3,3'dioctadecyloxacarbocyanine perchlorate; Invitrogen, D275) into the rostromedian neural and non-neural ectoderm in Newcultured chick embryos (New, 1955; protocol modified by Stern and Bachvarova, 1997). The injection was performed by applying buccal pressure to tubing connected with glass micropipettes filled with the dye solution. In some cases, homotopic grafts labeled with green fluorescent 5-(and-6)-carboxyfluorescein diacetate, succinimidyl ester (CFSE) (Molecular Probes) were performed as detailed by Fernández-Garre et al. (2002). The operated embryos were recorded photographically under fluorescent illumination using an Axiocam camera (Carl Zeiss Vision; München-Hallbergmoos), immediately after the graft or injection. The graft was detected by the green/red (DiI/DiO) fluorescent signal of the carbocyanines, respectively (Hatada and Stern, 1994). The embryos were cultured further until they reached stages $\mathrm{HH} 10-14$ and were then fixed overnight in cold 4\% paraformaldehyde (phosphate buffered $\mathrm{pH} 7.4$, $\left.0.1 \mathrm{M}, 4^{\circ} \mathrm{C}\right)$.

\section{PHOTO-OXIDATION OF CARBOCYANINE-DYE-LABELED CELLS}

To visualize permanently the dye-labeled cells, the fluorescence was photo-converted to an insoluble diaminobenzidine (DAB) by photo-oxidation (described by Selleck and Stern, 1991). The embryos were removed from the PFA and incubated with $\mathrm{DAB}$ solution (DAB in $0.1 \mathrm{M}$ Tris $\mathrm{pH} 7.4$ ) in the dark, at room temperature, for $1 \mathrm{~h}$. Each specimen was placed in a fairly deep glass cavity slide, covered with a coverslip. Under microscope epifluorescence the regions containing labeled cells were illuminated until all fluorescence disappears. After that, most operated specimens were systematically processed for in situ hybridization (ISH) with one of the mRNA probes described below.

\section{IN SITU HYBRIDIZATION (ISH)}

The embryos were hybridized following the protocol described by Streit and Stern (2001), Ferran et al. (in press). For this study we normally used digoxigenin-uridin triphosphate (UTP)labeled antisense chicken riboprobes. The standard visualization procedure with nitro blue tetrazolium (NBT)/5-bromo-4chloro-3'-indolyphosphate p-toluidine salt (BCIP) solution as chromogenic alkaline phosphatase substrate gave a dark blue reaction product for digoxigenin-UTP. The gene markers analyzed were Pitx2, Shh, Fgf8, Raldh3, Tcf4, Cytoqueratin-8, Hesx1, Dlx3, Pax6 and Six3.

Table 2 | Correlation of medio-lateral and dorso-ventral extent of derived graft domains with boundaries of gene expressions in the extra and neural areas.

\begin{tabular}{|c|c|c|c|c|c|c|c|c|c|}
\hline \multirow[b]{2}{*}{ Case } & \multirow[b]{2}{*}{ Gene expression } & \multirow[b]{2}{*}{ Fixation stage } & \multirow[b]{2}{*}{ Endod } & \multicolumn{3}{|c|}{ Ectoderm } & \multicolumn{3}{|c|}{ Secondary prosencephalon } \\
\hline & & & & Rostral & Medial & Lateral & ANB & SPall & Hypoth: os \\
\hline RPA-02 & Shh & $\mathrm{HH} 11+$ & + & + & +++ & & & & \\
\hline RPA-03 & Shh & $\mathrm{HH} 10$ & + & +++ & ++ & & & ++ & \\
\hline RPA-05 & Shh & $\mathrm{HH} 10+$ & + & +++ & & & + & + & \\
\hline RPA-25 & Fgf8 & $\mathrm{HH} 10+$ & & ++ & & & & & \\
\hline RPA-27 & Fgf8 & $\mathrm{HH} 11+$ & & ++ & +++ & & & & \\
\hline RPA-81 & Raldh3 & $\mathrm{HH} 11$ & & ++ & +++ & & & & \\
\hline RPA-80 & Raldh3 & $\mathrm{HH} 10$ & & + & +++ & & & & \\
\hline RPA-08 & - & $\mathrm{HH} 11$ & & +++ & +++ & & ++ & ++ & \\
\hline RPA-06 & Shh & $\mathrm{HH} 12$ & & & +++ & & & & \\
\hline RPA-22 & Fgf8 & $\mathrm{HH} 10$ & & ++ & & & ++ & + & \\
\hline RPA-30 & Fgf8 & $\mathrm{HH} 12$ & & + & & & ++ & ++ & \\
\hline RPA-09 & Shh & $\mathrm{HH} 10$ & & & & & $+?$ & ++ & ++ \\
\hline RPA-26 & Fgf8 & $\mathrm{HH} 12$ & & ++ & & + & + & + & \\
\hline RPA-10 & Shh & $\mathrm{HH} 9+$ & & + & & ++ & & & \\
\hline RPA-12 & Fgf8 & $\mathrm{HH} 9$ & & + & & ++ & & & \\
\hline RPA-18 & Fgf8 & $\mathrm{HH} 11$ & & & & +++ & & & \\
\hline RPA-84 & - & $\mathrm{HH} 9+$ & & & & +++ & & & \\
\hline RPA-88 & - & HH10 & & & & ++ & & & \\
\hline RPA-11 & Fgf8 & $\mathrm{HH} 11+$ & & & & & + & + & \\
\hline RPA-29 & Fgf8 & $\mathrm{HH} 9$ & & & & & & ++ & + \\
\hline RPA-20 & Fgf8 & $\mathrm{HH} 11$ & & & & & & ++ & + \\
\hline RPA-14 & Fgf8 & $\mathrm{HH} 11$ & & & & & & ++ & + \\
\hline RPA-87 & - & $\mathrm{HH} 11$ & & & & & & +++ & +++ \\
\hline
\end{tabular}

The relative amount of labeled cells filling the respective AP (medial-lateral) or DV (dorsoventral) territories is estimated roughly as "few cells" (+), "up to half the domain is labeled" (++) and "most or all the domain is labeled" $(+++)$. 

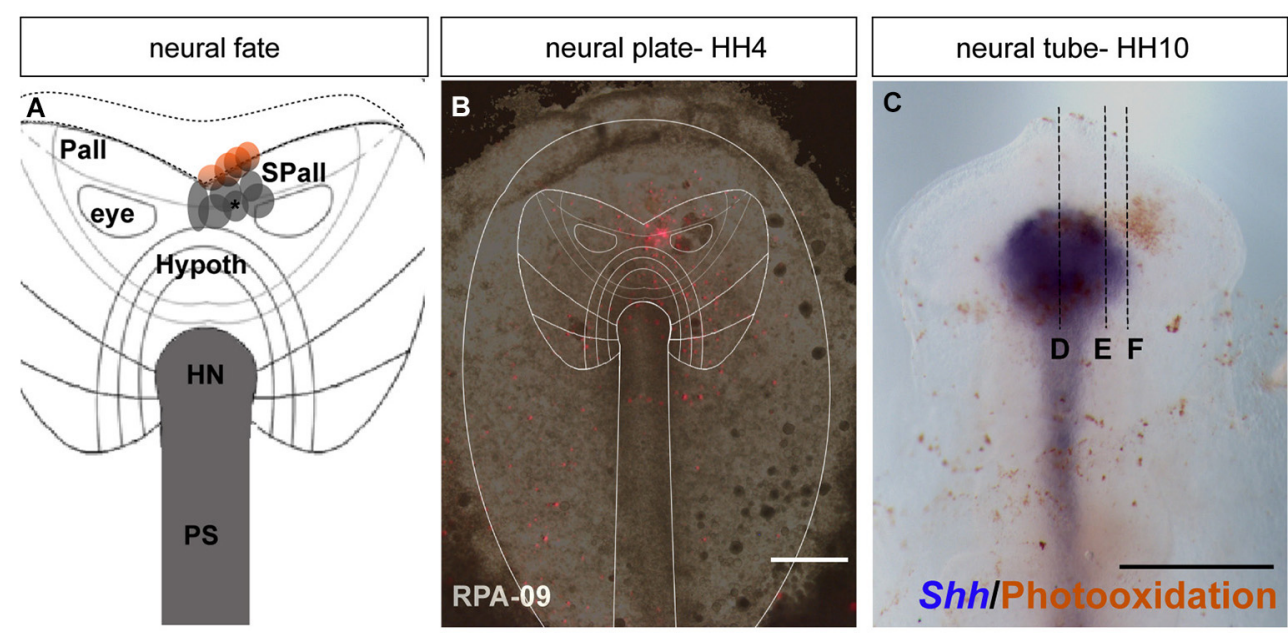

medial

lateral
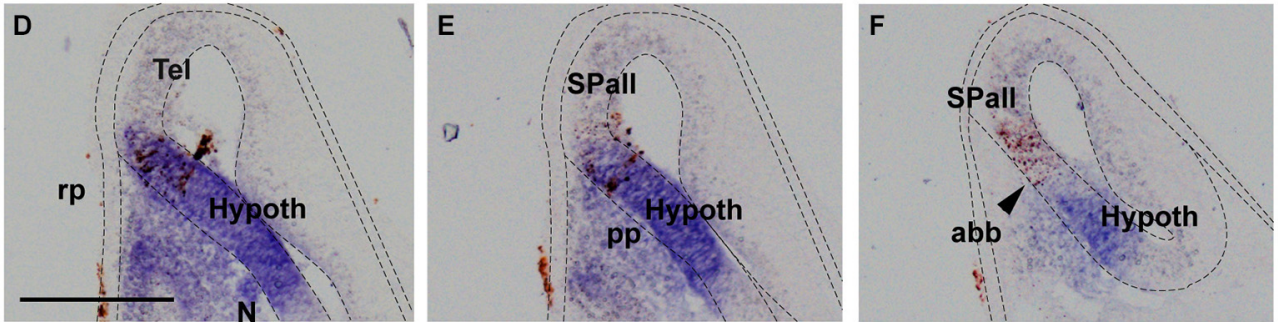

FIGURE 1 | Neural fate: analysis of the representative experimental case rostral plate area (RPA)-09. (A) Map of all studied grafts or injections corresponding with a neural fate. Those marked in red also labeled partially the anterior neural border and/or the ADH field. (B) The immediate bright field whole-mount view of case RPA-09 shows that the Dil injection was located within the neural plate, ranging between the prospective preoptic telencephalon and the more ventral basal hypothalamus. (C) At stage $\mathrm{HH} 10$, the embryo was whole-mount- hybridized for Shh (to visualize the hypothalamic basal plate expression), and the Dil was photo-oxidated with DAB. (D-F) Sagittal cryo-sections show that most labeled cells extend dorsoventrally within the rostral neural tube. In mid-sagittal sections, the injection-derived cells partially overlap the Shh positive cells of the hypothalamic basal plate. Laterally, positive cells appear in alar hypothalamic and telencephalic domains, where Shh expression is absent. Scale bars: $250 \mu \mathrm{m}$ in $\mathbf{( B , C )} ; 125 \mu \mathrm{m}$ in (D-F).

\section{IMMUNOHISTOCHEMITRY (IHC) AND TISSUE PROCESSING}

Cells derived from the CFSE-labeled grafts were visualized after the ISH reaction. The embryos were immunoreacted with anti-fluorescein Fab fragments conjugated to horseradish peroxidase (anti-fluorescein-peroxidase, horseradish (POD); 1:500; Boehringer; Mannheim) following standard protocols (Fernández-Garre et al., 2002; Ferran et al., in press). Afterwards the embryos were cryoprotected overnight in $10 \%$ sucrose in PBS, and embedded in 10\% gelatin and 10\% sucrose in PBS. The blocks were cryostat-sectioned 10-12 $\mu \mathrm{m}$-thick in the sagittal plane and mounted with Mowiol.

\section{IMAGING}

Images were captured with an Axiocam digital camera (Carl Zeiss Vision; München-Hallbergmoos). Digital images were processed with Photoshop ${ }^{\circledR}$ CS4 11.0.2 and ImageJ (Fiji) software. Representative images were used to draw vectorial schemata with Adobe Illustrator CS4.

As previously described (Streit, 2002), embryos subjected to ISH shrink significantly when heated in the presence of formamide and detergent. Two approaches were used to overcome this problem when comparing the position of DiIlabeled cells. In some embryos the images obtained from in situ hybridized embryos were increased by $10 \%$ and aligned to landmarks on the fluorescence image to produce a montage. In other embryos, the DiI fluorescence was photoconverted with DAB (Izpisúa-Belmonte et al., 1993) before ISH. This approach allows DiI labeled cells to be seen directly in the whole-mount in situ processed embryo and confirms the assumptions made by adjusting the magnification of separately obtained images, as described above (Sanchez-Arrones et al., 2012).

\section{RESULTS AND DISCUSSION EXPERIMENTAL FATE MAPPING AND EARLY MORPHOGENETIC TRACING OF THE PROSPECTIVE ADH}

During chick development, the $\mathrm{ADH}$ placode (presumptive Rathke's pouch) becomes morphologically identifiable as a thickened patch of epithelium at stages HH12-14 (Romanoff, 1960). At this moment the $\mathrm{ADH}$ is molecularly segregated from the adjacent olfactory placode, both being ectodermal placodal specializations that lie outside the neural tube. In order to know precisely the position of the prospective 

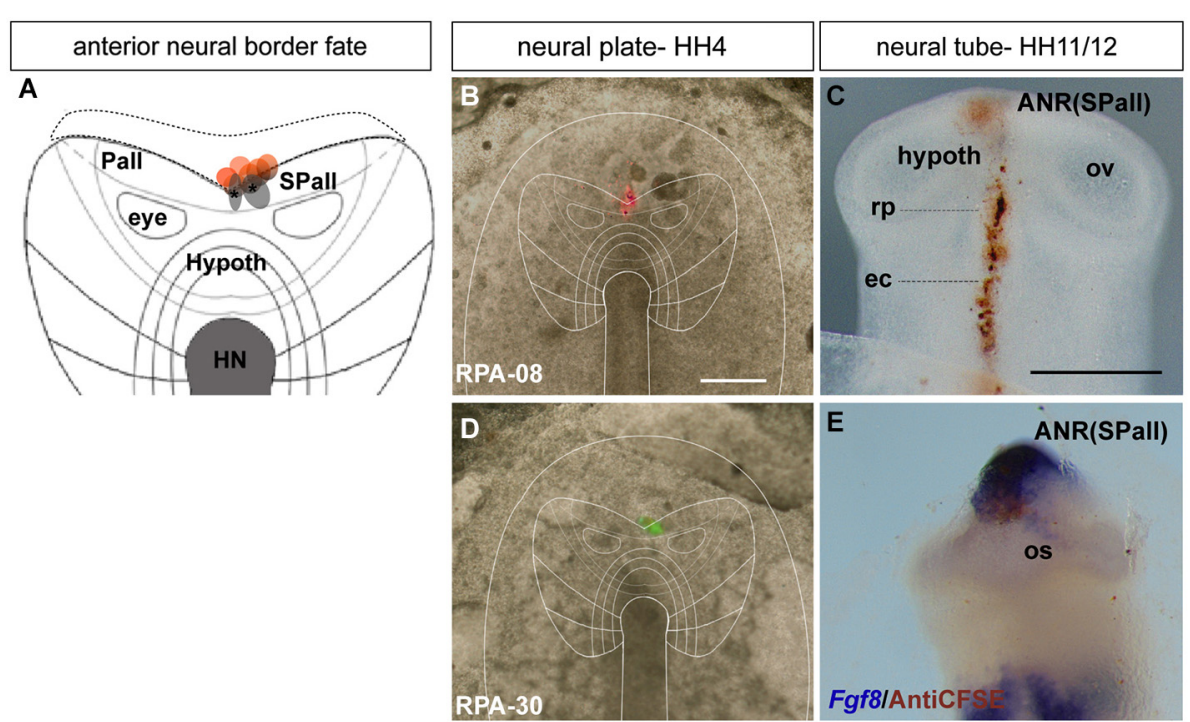

FIGURE 2 | Anterior neural border fate: analysis of the experimental cases RPA-08 and RPA-30. (A) Map of studied grafts or injections correlative with an anterior neural border fate. The grafts marked in red also produced ADH labeling. (B,D) Cases RPA-08 and RPA-30 in bright-field whole-mount view, illustrating an injection and a graft, respectively, targeting the previously fate-mapped rostral neural boundary. (C) At stage HH11-12, the Dil-labeled RPA-08 cells were found in a median elongated strip extending across the neural/non-neural midline, with part of the labeled cells within the telencephalic domain and another part extending into the prospective Rathke's pouch and median head ectoderm approaching the anterior intestinal portal. The graft-derived cells largely were located at stage $\mathrm{HH} 12$ laterally at the prospective subpallium and ventrally at the prospective optic stalk. (E) In case RPA-30 some labeled cells overlap with Fgf8 expression in the neural and non-neural ectodermal cells. Scale bars: $250 \mu \mathrm{m}$.
$\mathrm{ADH}$ primordium relative to the neural telencephalic and neurohypophyseal primordia at earlier neural plate stages, when the $\mathrm{ADH}$ is not histologically distinct, we performed fatemapping experiments combined with mappings of neural and non-neural maker genes. To this end, the anterior midline ectoderm was labeled systematically using small fluorescent grafts or small single injections of the fluorescent dyes $\mathrm{DiI}$ or $\mathrm{DiO}$ at stage $\mathrm{HH} 4 / 5$ at different dorsoventral levels (the node represents the ventralmost median position and the median non-neural ectoderm lies topologically dorsal to the ANR (Fernández-Garre et al., 2002; Sanchez-Arrones et al., 2009). The derived domains of these grafts and injections were examined in comparison to a selected gene marker between stages $\mathrm{HH} 10$ and $\mathrm{HH} 12$, when the placodal cells start to be morphologically distinguishable (thickened and invaginated) from the adjacent ectoderm. The experimental cases selected for this analysis are illustrated in the Figures 1-4. These show schemata which respectively locate the set of grafts and injections grouped at the midline which produced derivatives at either the anterior median neural domain (preoptic telencephalon and hypothalamus; Figure 1), the anterior neural border domain (ANR; Figure 2), anterior median pre-placodal domain (ADH; Figure 3) and anterior nonplacodal ectoderm and endoderm (Figure 4). The size, distance from the node, and angular radial position of the grafts and injections relative to the nodal median radius appears listed in Table 1. We will describe below six representative cases out of a total of 23, ordered according to their progressively more dorsal fates; neural fate (RPA-09), ANR (RPA-08 and RPA30), anterior median pre-placodal domain (RPA-27, RPA-02 and RPA-80) and anterior non-placodal ectoderm/endoderm (RPA-06).

\section{Anterior median neural cells}

In the case RPA-09, a DiI injection was placed across the prospective alar/basal boundary of the anterior neural plate (anp), roughly $170 \mu \mathrm{m}$ distant from the node (Figures 1A,B, compare (Sanchez-Arrones et al., 2009; Table 1). At stage HH10, labeled cells derived from the injection appeared precisely across the molecular limit separating the alar and basal plates (bp) of the secondary forebrain (Figure 1C). This specimen was processed to detect Shh signal, which represents a gene expressed selectively at this stage throughout the floor and bp of the secondary prosencephalon (SP; Bardet et al., 2010). Some Shh-positive cells overlapped with brown-labeled cells derived from the injection (implying the latter fell partially upon prospective basal hypothalamus), whereas other injection derivatives overlapped with more dorsal Shh-negative cells located in the median alar SP (prospective alar hypothalamus and/or preoptic subpallial telencephalon (Figures 1D-F; see Cobos et al., 2001; Bardet et al., 2010)).

\section{Anterior neural border cells}

In the case RPA-08, a DiI injection targeting the ANR was placed more dorsally across the border between neural and nonneural (preplacodal) domains at a distance of $286 \mu \mathrm{m}$ from the node (Figures 2A,B; see Sanchez-Arrones et al., 2012). At stage HH11, the DiI-labeled cells were located at the midline of the prospective septal roof plate of the subpallial telencephalon and 

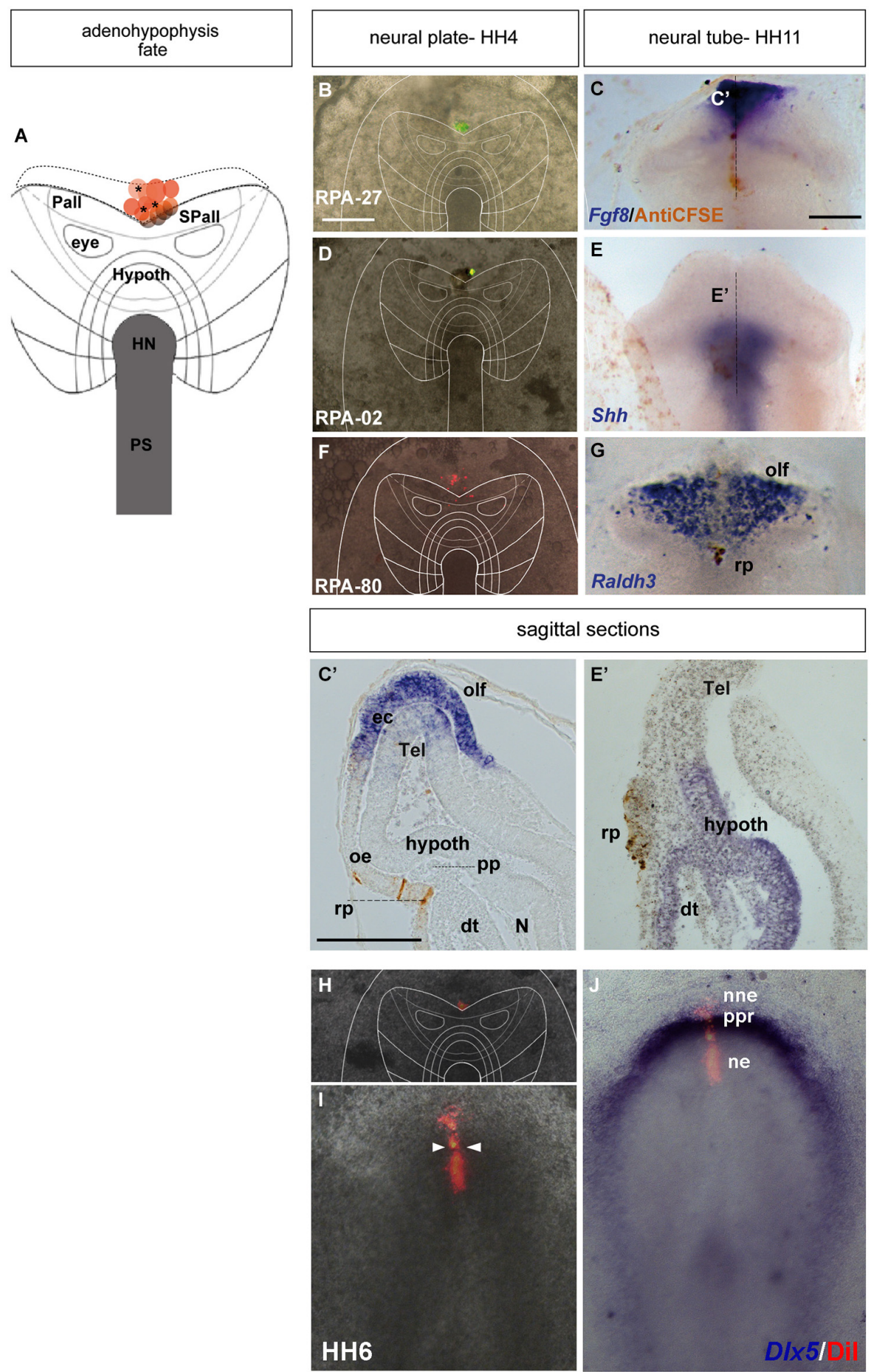

FIGURE 3 | Adenohypophyseal fate: analysis of the experimental cases RPA-27, RPA-02 and RPA-80. Initial median cell movements. (A) Map of all studied grafts or injections corresponding with partial adenohypophyseal fate. (B,D,F,H) Combined fluorescent and bright field images of representative $\mathrm{HH} 4$ chick embryos in which a graft (B) or either a Dil (D) or DiO injection $\mathbf{( F , H )}$ was placed at the median non-neural ectodermal region. (C, $\left.\mathbf{C}^{\prime}\right)$ At stage $\mathrm{HH} 11$, the graft-derived cells were located in the rostromedian non-neural ectoderm, largely coinciding with the Fgf8-negative Rathke's pouch rudiment. $\left(\mathbf{E}, \mathbf{E}^{\prime}\right)$ The prospective Rathke's pouch tissue, flipped over into external contact with the neural terminal wall, already has elongated to the level of the Shh-positive prospective hypothalamic basal plate. $(\mathbf{F}, \mathbf{G})$ In case RPA-80, the labeled non-neural cells of the ADH primordium clearly appeared at the medial head ectoderm, within the space that separates the bilateral Raldh3-positive olfactory placodes, whose cells remained unlabeled. (I,J) Simple fluorescent and combined fluorescent and bright field images of the case illustrated in $(\mathbf{H})$, counterstained with D/x5 whole-mount ISH, showing the elongated median labeled trace of ectodermal tissue extending from the (Continued) 


\section{FIGURE 3 | Continued}

preplacodal field (ppf) into the ventrally displaced ADH primordium, at stage $\mathrm{HH}$ 6. Arrowheads in (I) mark the site of the original injection (see also Sanchez-Arrones et al., 2012). Scale bar: $250 \mu \mathrm{m}$ in (B,C); $125 \mu \mathrm{m}$ in (C')

also formed a thin stripe extending along the midline of the ADH placode (Rathke's pouch) and neighboring head ectoderm (Figure 2C). In other experimental embryos of this group, such as case RPA-30, in which a fluorescent graft was inserted at the rostral neural border approximately $273 \mu \mathrm{m}$ distant from the node (Figures 2A,D), slightly laterally to the RPA-08 injection, the grafted cells appeared at stage HH12 (closed neural tube) exclusively at the prospective median telencephalon, represented by the Fgf8-expressing ANR area of the presumptive septum and the preoptic area, without labeling the $\mathrm{ADH}$ primordium (Figure 2E; see Cobos et al., 2001). Some labeled (grafted) cells were observed as well at the optic stalk (alar hypothalamus), which is also Fgf8 positive (Figure 2E; Crossley et al., 2001). The positional similarity of the experiments producing both neural and placodal derivatives vs. those producing only neural derivatives suggests close vicinity between both domains across the neural/non-neural border.

\section{Anterior preplacodal domain; prospective ADH precursors}

The ADH precursors were labeled specifically in the next three cases: RPA-27 RPA-02 and RPA-80. In case RPA-27, a graft was placed more dorsally along the midline ectoderm, at a $260 \mu \mathrm{m}$ distance from the node (Figure 3B), whereas in RPA02 a DiI injection was introduced at $280 \mu \mathrm{m}$ from the node (Figure 3D). In the whole-mounted embryos photographed at stage HH11, the graft-derived cells were found at the rostral midline ectoderm site which contains the thickened Rathke's pouch (see Cajal et al., 2012); the latter and the surrounding rostral ectoderm do not express Fgf8 (Figures 3C,C'). Rathke's pouch, already occupying the stomodeal roof, lies below the prechordal plate (pp), which in its turn underlies the prospective hypothalamic bp (Shh-positive domain; Figures 3E,E'; GarcíaCalero et al., 2008). The grafted/injected ADH areas showed intercalation of labeled cells with unlabeled ones, suggesting that a longitudinal intercalation mechanism is involved in the early morphogenesis of the ADH placode (see also SanchezArrones et al., 2009). Laterally, further cells derived from the graft extended into the rostral head ectoderm (shown in the RPA-02; Figures $\left.3 \mathbf{E}, \mathbf{E}^{\prime}\right)$, but not into the olfactory placode (Raldh3-positive cells; shown in the RPA-80 case; Figure 3G).

Consistently with this idea, we recently reported that a longitudinal median intercalation mechanism also obtains during cell movements of the anterior proneural zone at neural plate stages. In fact, the median cells are compactly stretched across the entire ectodermal midline, including the neural and non-neural territories (shown in Figures 3H-J; see also Sanchez-Arrones et al., 2012); this suggests that midline cells display a differential intercalative behavior compared with nearby more lateral (caudal) cells.

\section{Anterior ectoderm and endoderm}

In case RPA-06, a single DiO injection (green fluorescence) was placed at $\mathrm{HH} 5$ at the rostromedian non-neural ectoderm and underlying rostral endoderm (Figures 4A,B; see Stalsberg and DeHaan, 1968; Kimura et al., 2006). The embryo survived until $\mathrm{HH} 12$, and the resulting fluorescent-labeled cells were photooxidated, while the specimen was hybridized for Shh (Figure 4C). Most labeled cells appear located in or superficial to the rostral digestive tube (dt; Figure 4D. The Shh expression is visible at the prospective basal and floor plates of the SP (hypothalamus). Axial mesodermal tissues including the $\mathrm{pp}$ and the notochord are also positive for Shh (Withington et al., 2001; García-Calero et al., 2008). Some DiO-labeled cells were detected in the head ectoderm located in front of the pp (Figure 4D).

These results indicate that the fates of ectodermal cells occupying the rostral midline are well segregated at early neural plate stages. The ADH precursors occupy strictly extraneural positions (Figure 7). These cells separate the more dorsal midline ectoderm (prospective oral and head ectoderm) from the anterior neural border cells (ANR; prospective roof and median alar subpallial domains of the telencephalon). The latter territories are relatively distant from the prospective $\mathrm{NH}$, located much more ventrally at neural plate stages, within the prospective basal hypothalamus. Once the neural tube is closed and the telencephalic vesicles start to emerge bilaterally, the $\mathrm{ADH}$ precursors restricted to the extra-neural midline (as well as the underlying rostral endoderm) are bent by the cephalic fold as by a hinge into the stomodeal roof. Both the preopto-hypothalamic acroterminal midline and the median cephalic ectoderm are stretched considerably by the growth of the head and associated cell intercalation phenomena (Sanchez-Arrones et al., 2009, 2012). The $\mathrm{ADH}$ primordium thus results separated from the median telencephalon and develops a new close relationship with the basal hypothalamus (prospective $\mathrm{NH}$ ), thanks to the vacation of the space previously occupied by the prechordal mesoderm.

\section{MOLECULAR TRACING OF ADENOHYPOPHYSIAL DEVELOPMENT}

The development of the pituitary gland is a multistep morphogenetic process controlled by a genetic program (Sheng et al., 1997; Treier et al., 1998). Though we know various molecular traits involved in specification and differentiation of the different cell types of the $\mathrm{ADH}$ (Sheng and Westphal, 1999), little is known about the molecular patterns activated during the earliest stages of $\mathrm{ADH}$ development. Assuming a non-neural placodal nature of the $\mathrm{ADH}$ primordium (see results above, and references cited in the Introduction), our next aim was to examine the molecular signals that first specify differentially the rostral pre-placodal ectodermal region vs. the anterior neural ectoderm at neural plate stages; secondly, we wanted to study the initial regionalization of the presumptive preplacodal territory into $\mathrm{ADH}$ vs. olfactory placodes at early neural tube stages, during the formation of Rathke's pouch; finally, our attention centered on the onset of $\mathrm{ADH}$ molecular regionalization into the anterior and intermediate pituitary gland lobes. 

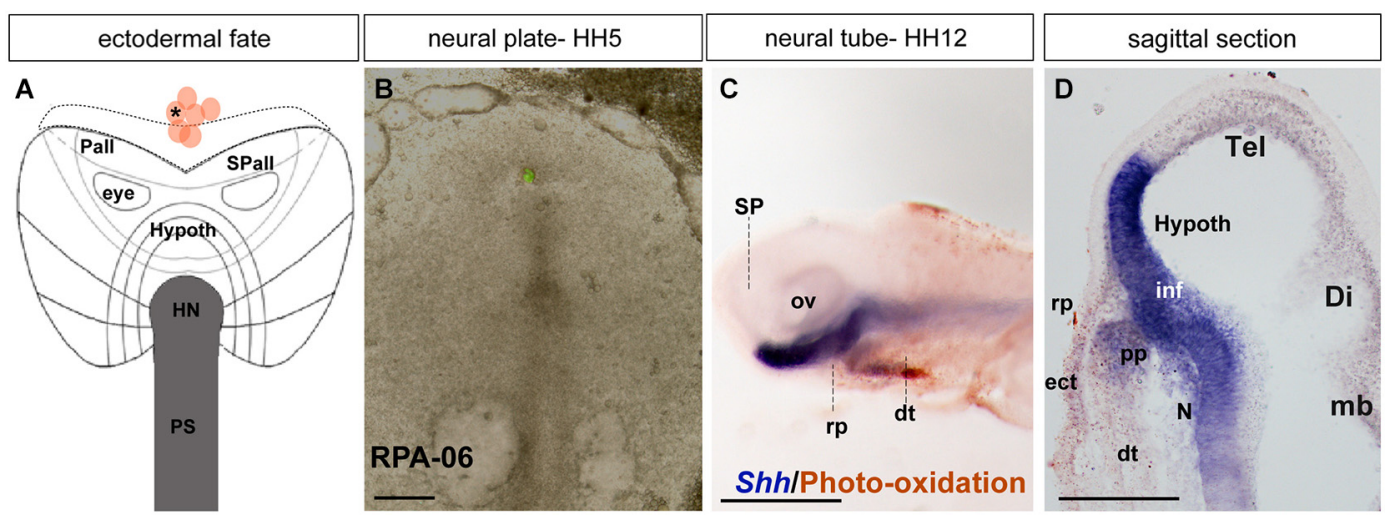

FIGURE 4 | Ectodermal fate: analysis of the experimental case RPA-06. (A) Map of studied grafts or injections exclusively corresponding to non-neural head ectoderm at the midline. (B) Bright-field image of representative case RPA-06 illustrating labeled cells (corresponding to dark dot in A) located largely in the rostral ectoderm beyond the ADH field locus. (C) Side view of the whole-mount HH12 specimen after photo-oxidation of the Dil and hybridization for Shh (neural basal and floor plate); Dil labeled cells appear in the median head ectoderm and slightly extend into the digestive tube. (D) A mid-sagittal section through the specimen shows that the brown-stained labeled cells lie outside the Rathke's pouch primordium (rp). Scale bars: $250 \mu \mathrm{m}$ in (B); $125 \mu \mathrm{m}$ in (D).

\section{Early ADH development: paraneural pre-placodal primordium from HH4 to HH12}

In order to visualize the potential $\mathrm{ADH}$ primordium we mapped the Pitx2 transcription factor. This gene is involved in head mesoderm patterning (Bothe et al., 2011), and in the establishment of embryonic left-right asymmetry and the fate of precardiac cells during cardiogenesis (García-Castro et al., 2000; Lopez-Sanchez et al., 2009). It also plays a key role during

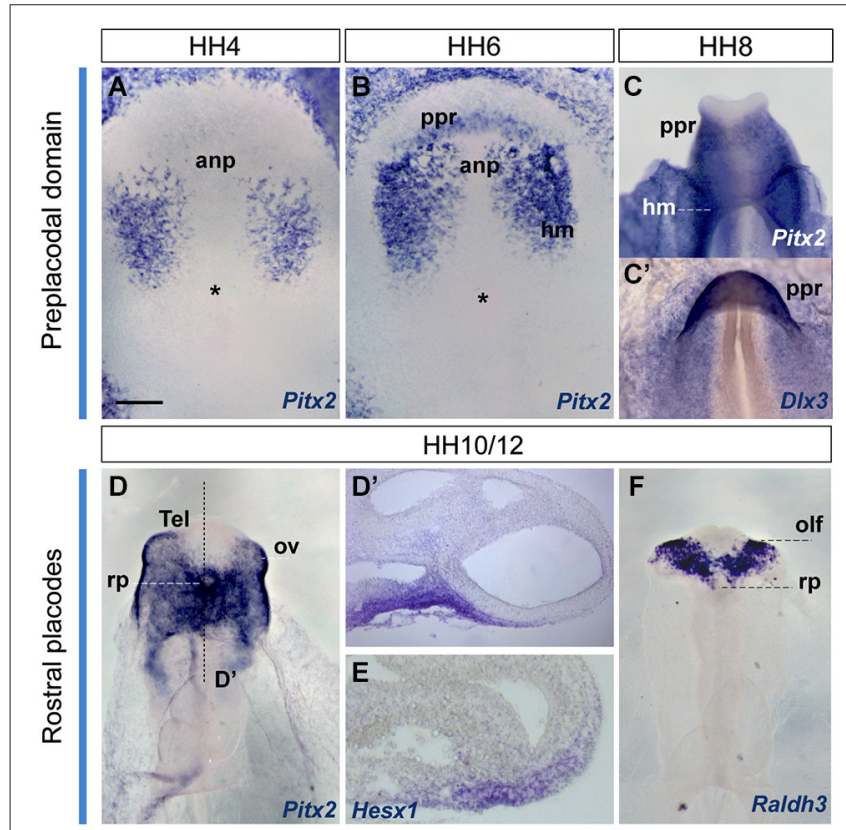

FIGURE 5 | Early gene expression at the ADH primordium. Neural plate and neural tube whole mounts hybridized with Pitx2, D/x3, Hesx 1 and Raldh3. The images are shown in a ventral view. The node is marked by an asterisk in some of the images. Scale bar: $250 \mu \mathrm{m}$.
$\mathrm{ADH}$ development at neural tube stages, correlative with the emerging Rathke's pouch (chick, Sjödal and Gunhaga, 2008; Parkinson et al., 2010; Xenopus, Schweickert et al., 2001; mouse, Drouin et al., 1998; Suh et al., 2002). Other Pitx family members as Pitx 1 and Pitx3 were well characterized during early ADH development, at pre-placodal stages (mouse, Lanctôt et al., 1997; zebrafish, Dutta et al., 2005); however, the early Pitx2 expression was not yet addressed. We thus examined Pitx2 expression by ISH in whole-mount chick embryos and cross-sections, comparing with other genes known to be involved in pre-placodal/placodal specification, such as $D l \times 3$ (expressed in non-neural ectoderm; Dutta et al., 2005; Khudyakov and Bronner-Fraser, 2009), Hesx1 (an ADH placode marker; Hermesz et al., 1996), and Raldh3 (an olfactory placode marker; Sabado et al., 2012; Figure 5). Initially, at HH4, Pitx2 signal was only present in the head mesenchyme (Figure 5A). Shortly afterwards, at HH6+/7-HH8, when the anterior neural border becomes sharp (SanchezArrones et al., 2012), an ectodermal Pitx2-positive domain was detected in the rostral head fold, which coincides with the Dlx3-positive paraneural pre-placodal area (Figures 5B,C'); a similar result was reported during early placodal differentiation in mouse embryos and zebrafish larvae. At early closed neural tube stages, HH10-HH11, this paraneural Pitx2 signal overlaps the expression domain of the placodal marker Hes $x 1$, precisely in the thicker median placodal cells, which are held to represent the adenohypophyseal placode (Figures 5D,E; see also Sjödal and Gunhaga, 2008). Raldh3-positive cells were detected instead bilaterally in the prospective olfactory placode cells and the surrounding ectoderm, whereas Raldh3 expression was completely absent at the ADH placode (Figure 5F). Accordingly, at stages HH10-11 the Dlx3/Pitx2-expressing primary paraneural pre-placodal ectodermal domain becomes regionalized in cellular and molecular terms, forming rostrally the median Pitx2/Hesx1positive $\mathrm{ADH}$ placode and bilaterally the Raldh3-positive olfactory placodes (Bailey et al., 2006). 

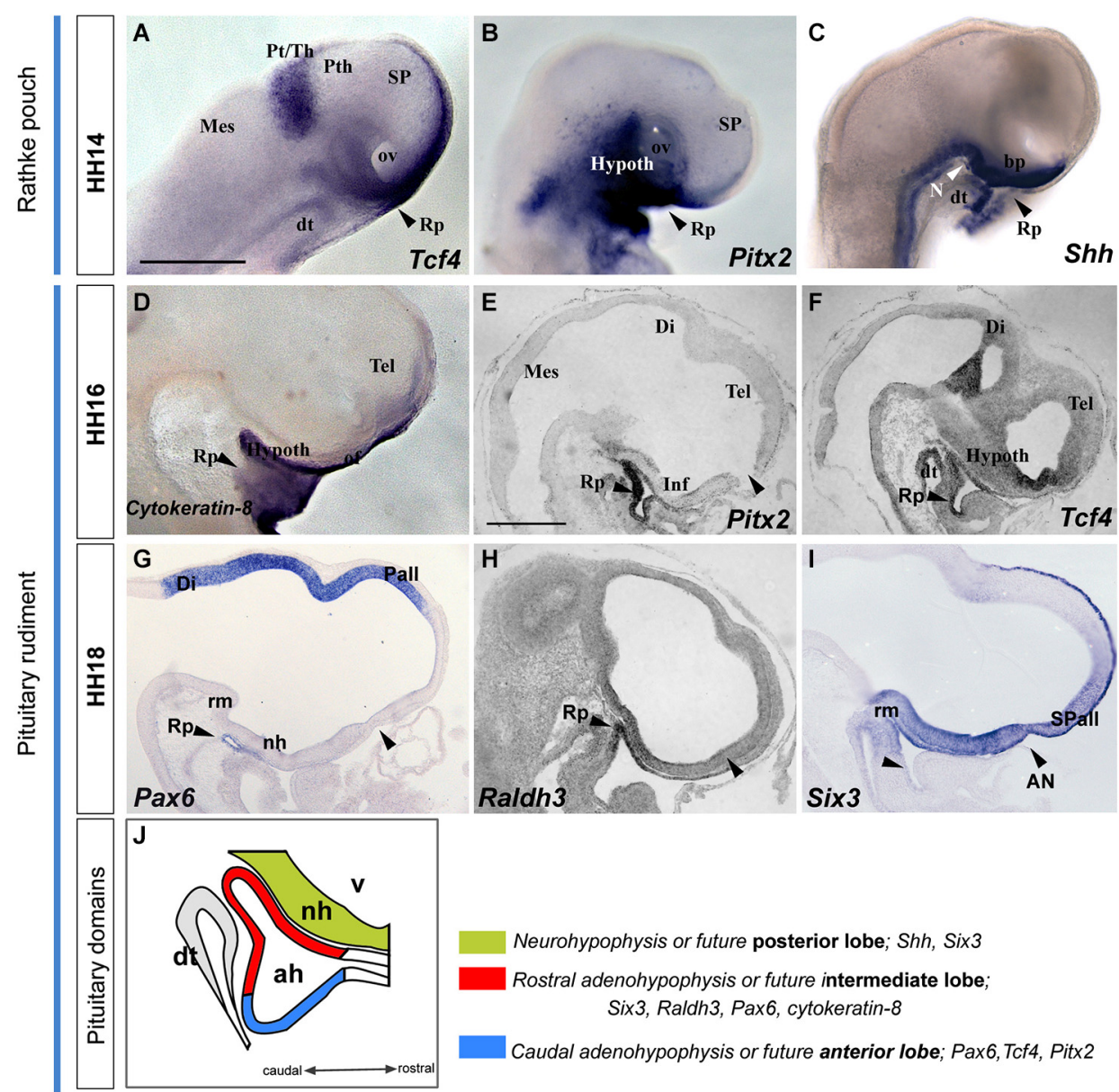

Raldh3

Six 3

Neurohypophysis or future posterior lobe; Shh, Six3

Rostral adenohypophysis or future intermediate lobe Six3, Raldh3, Pax6, cytokeratin-8

Caudal adenohypophysis or future anterior lobe; Pax6, Tcf4, Pitx2

FIGURE 6 | Latter molecular expression at the ADH and NH primordium, pituitary rudiment. This panel shows the expression pattern of some genes involved in ADH and $\mathrm{NH}$ development. (A-I) Whole-mount hybridized embryos for Tcf4, Pitx2, Shh, Cytoqueratin-8, Pax6, Raldh3 and Six3. (J) The schema represents the pituitary rudiment and its initial molecular subdivision. Scale bar: $250 \mu \mathrm{m}$.

\section{Later development of the ADH: Rathke pouch rudiment from HH14 to HH18}

The developing pre-placodal domain subsequently undergoes changes in cell shape that drive the histologic differentiation of the placodes. The first change observed is a thickening of the placodal cells, which is generally accompanied by incipient invagination. The $\mathrm{ADH}$ placode starts to transform into a recognizable Rathke's pouch during stage HH12 (Romanoff, 1960), when the neural tube is bending at the cephalic flexure. Parallel growth of the cephalic fold, with rostroventral protrusion of the embryonic head and intercalative elongation of the median preopto-opto-hypothalamic part of the neural plate, causes the oro-pharyngeal plate (originally formed rostral to the pre-placodal ectodermal band) to be internalized into the depth of the growing stomodeum. The median part of the placodal band sharply hinges under the closing rostral neuropore into the stomodeal roof, thus inverting its apico-basal orientation as it also undergoes intercalative elongation (Figure 7). The median stomodeal cells derived from the primary $\mathrm{ADH}$ placodal domain (prospective Rathke's pouch) thus result placed underneath the tuberal hypothalamus (prospective neurohypophyseal primordium), though the two primordia are still mutually separated by the respective basal membranes and interposed prechordal mesoderm. Closure of the rostral neuropore and differential morphogenesis of the non-median tissues (mainly the evaginating telencephalic and eye vesicles, plus the olfactory placodes) increasingly separates the stomodeal ADH primordium from its earlier telencephalic neighbors (by stretching and growth of the interposed non-neural ectoderm), and the fused ANR transforms into the neural commissural septal plate (Puelles et al., 1987; Cobos et al., 2001). By stage HH14 the invaginated $\mathrm{ADH}$ primordium progressively forms the roof of Rathke's pouch under the median tubero-infundibular forebrain area. From this stage onwards the $\mathrm{ADH}$ cells lie progressively closer to the presumptive $\mathrm{NH}$ (though the evaginated $\mathrm{NH}$ organ only emerges later, at stage $\mathrm{HH} 26$ in chick embryos), and molecular regionalization of the $\mathrm{ADH}$ primordium starts, as the stalk of Rathke's pouch degenerates and disappears.

We illustrate in Figure 6 the correlative changes of some molecules involved in $\mathrm{ADH}$ and $\mathrm{NH}$ development, namely 

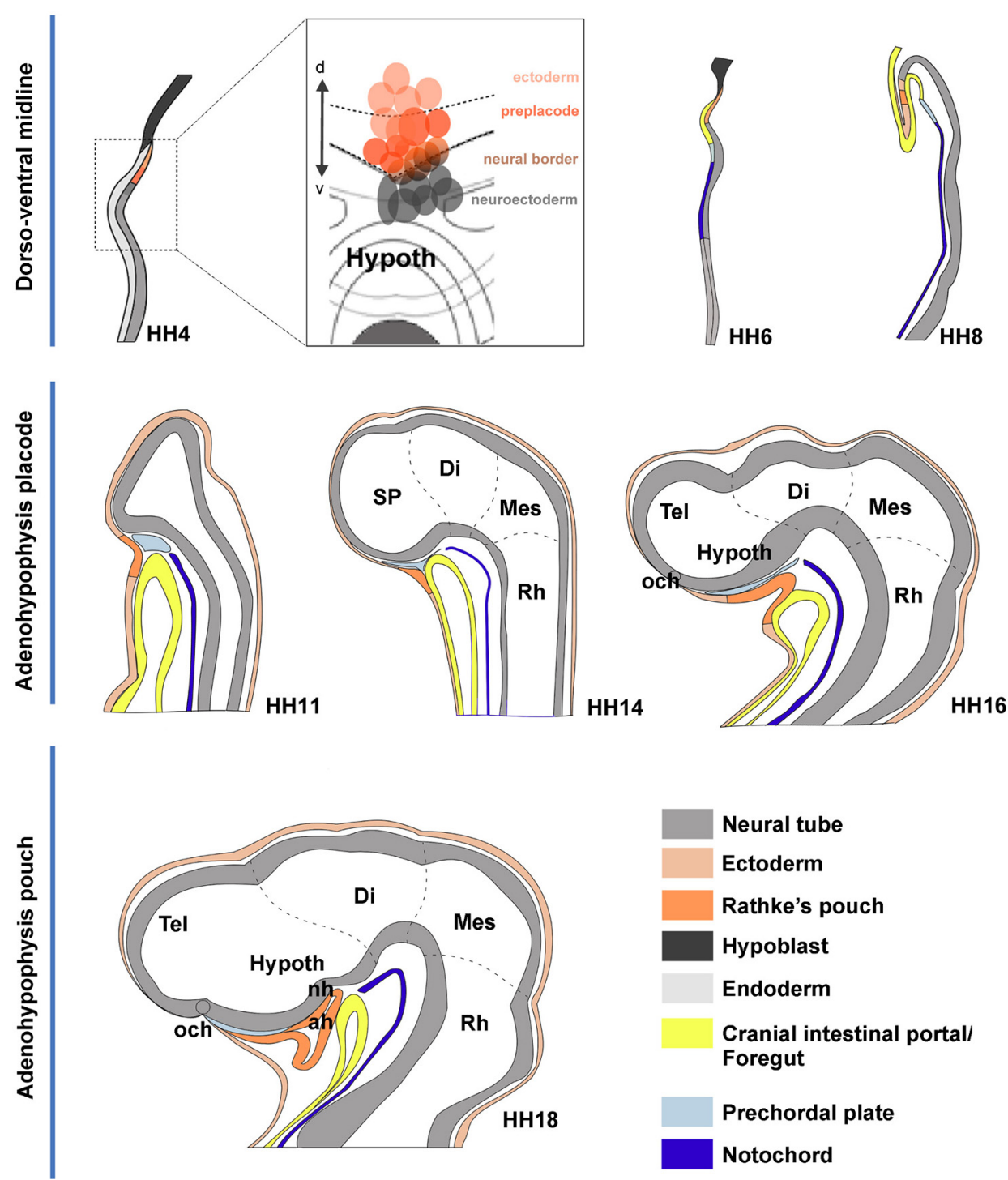

FIGURE 7 | Schematic summary of proposed morphogenetic events leading to the development of the adenohypophysis across neural plate and neural tube stages. These schemata each represent in general the changing sagittal midline of chick embryos at different developmental stages. The dashed lines delimit the main rostrocaudal subdivisions of the neural tube. (HH4) The initial schema illustrates a median section through the early neural plate, marking tissue corresponding to hypoblast (black), rostral endoderm (pale gray) and neural plate or tube (gray). The prospective $A D H$, representing median non-neural ectoderm, is coded in deep orange. The deduced flat fate map of the median anterior head domain is illustrated in the insert at the side, showing in deep red the labeled sites identifying by fate the ADH field, in contrast to rostral neuroectoderm sites (gray field) and non-ADH head ectoderm sites (light red). (HH6) This schema is similar to the $\mathrm{HH} 4$ one, though we distinguish now the endodermal primordium of the anterior intestinal portal (yellow) and the notochordal tissue (deep blue). (HH8) The head fold develops, causing the $\mathrm{ADH}$ field to flip over in a hinge-like motion under the anterior intestinal portal, though it still remains transiently attached by head ectoderm to the anterior neural ridge (rostral neuropore still open). (HH11) Neurulation is nearly finished at this stage; we identify the head ectoderm (weak orange) and the prechordal plate mesoderm (weak blue) at the tip of the notochord (the latter lies under the prospective mammillary pouch); note the prechordal tissue transiently separates the ADH rudiment from the basal hypothalamus. (HH14,HH16) The prechordal tissue gradually migrates dorsalward in front of the terminal hypothalamic wall, allowing the stomodeum to form and the ADH to approach the hypothalamus. (HH18) The prechordal cells have migrated away, being now in contact with the alar median hypothalamus (chiasmatic region) and the prospective preoptic telencephalon (terminal lamina); they leave the basal tuberal hypothalamus free for close contact with the ADH primordium; this rostroventral tuberal territory includes the prospective neurohypophysis $(\mathrm{NH})$, whose evagination is first observable several stages later, at HH26. the markers with Tcf4, Pitx2, Shh, Cytoqueratin-8, Pax6, Raldh3 and Six3. At HH14, the oral stomodeal ectoderm containing Rathke's pouch is distinguished molecularly by selective expression of Tcf4, Pitx2 and Shh (Figures 6A-C; Sjödal and Gunhaga, 2008). At HH16-18, the ADH pouch underlies the $\mathrm{NH}$ primordium and the prospective tuberal region (see sagittal sections, Figures 6E-I; see also Bardet et al., 2010), where Pax6 and Cytokeratin-8 are expressed (Figures 6D,G,J). 
Furthermore, we noted the onset of $\mathrm{ADH}$ regionalization into two domains, the future anterior and intermediate lobes (Sheng and Westphal, 1999; Rizzoti and Lovell-Badge, 2005; Reyes et al., 2008). Whereas Tcf4 and Pitx2 signals delineated the presumptive anterior part of the ADH (Figures $6 \mathrm{E}-\mathrm{G}, \mathbf{J}$ ), Six3 and Raldh3 expression appears restricted to the future intermediate $\mathrm{ADH}$ lobe, which underlies the presumptive $\mathrm{NH}$ or posterior pituitary lobe (Six3 and Shh-positive domain; Figures 6H-J).

These data jointly suggest that Pitx2 is an early preplacodal marker that intervenes during molecular regionalization of the rostral preplacodal domain into olfactory and $\mathrm{ADH}$ placodes. The ADH rudiment is later partitioned molecularly into two subdomains, the prospective intermediate and anterior lobes, which lie underneath the prospective $\mathrm{NH}$ or posterior lobe, contained for a while within the tubero-infundibular hypothalamic wall.

\section{CONCLUSION}

Our analysis corroborates the median extraneural locus of the ectodermal $\mathrm{ADH}$ primordium at $\mathrm{HH} 4$, coinciding with the molecularly distinct median preplacodal domain. Data were obtained indicating that this midline locus is involved in particularly strong dorsoventral intercalative movements, oriented orthogonally to the neural/nonneural boundary. Such movements apparently represent part of the forces that quickly separate the $\mathrm{ADH}$ primordium from the ANR (as observed already at HH6; see Figures 3I,J), complementing other forces derived from surrounding tissues involved in head fold development, forebrain neurulation and brain and eye growth. At the end of median intercalation (e.g., HH8), the ectodermal $\mathrm{ADH}$ anlage appears hinged downwards under the head fold, and it already occupies a position close to its subsequent apposition to the basal hypothalamus. However, this contact only occurs somewhat later (HH12), after the initially intervening prechordal plate cells move past the median basal hypothalamus into more dorsal neighborhoods (Figure 7).

\section{ACKNOWLEDGMENTS}

We are grateful to P. Bovolenta, S. Martinez, H. Nakamura, J. Rubenstein, A. Simeone, and M. Studer for kindly provided cDNA clones. This work was supported by the Spanish Ministry of Economy and Competitiveness grant BFU2008-04156 and the SENECA Foundation 04548/GERM/06 (no. 10891) to Luis Puelles.

\section{REFERENCES}

Bailey, A. P., Bhattacharyya, S., Bronner-Fraser, M., and Streit, A. (2006). Lens specification is the ground state of all sensory placodes, from which FGF promotes olfactory identity. Dev. Cell 11, 505-517. doi: 10.1016/j.devcel.2006. 08.009

Bardet, S. M., Ferran, J. L., Sanchez-Arrones, L., and Puelles, L. (2010). Ontogenetic expression of sonic hedgehog in the chicken subpallium. Front. Neuroanat. 4:28. doi: $10.3389 /$ fnana. 2010.00028

Bothe, I., Tenin, G., Oseni, A., and Dietrich, S. (2011). Dynamic control of head mesoderm patterning. Development 138, 2807-2821. doi: 10.1242/dev. 062737

Cajal, M., Creuzet, S. E., Papanayotou, C., Sabéran-Djoneidi, D., Chuva de Sousa Lopes, S. M., Zwijsen, A., et al. (2014). A conserved role for non-neural ectoderm cells in early neural development. Development 141, 4127-4138. doi: 10.1242/dev.107425

Cajal, M., Lawson, K. A., Hill, B., Moreau, A., Rao, J., Ross, A., et al. (2012). Clonal and molecular analysis of the prospective anterior neural boundary in the mouse embryo. Development 139, 423-436. doi: 10.1242/dev.075499

Cobos, I., Shimamura, K., Rubenstein, J. L., Martínez, S., and Puelles, L. (2001). Fate map of the avian anterior forebrain at the four-somite stage, based on the analysis of quail-chick chimeras. Dev. Biol. 239, 46-67. doi: 10.1006/dbio.2001. 0423

Couly, G. F., and Le Douarin, N. M. (1985). Mapping of the early neural primordium in quail-chick chimeras. I. Developmental relationships between placodes, facial ectoderm and prosencephalon. Dev. Biol. 110, 422-439. doi: 10. 1016/0012-1606(85)90101-0

Couly, G. F., and Le Douarin, N. M. (1987). Mapping of the early neural primordium in quail-chick chimeras. II. The prosencephalic neural plate and neural folds: implications for the genesis of cephalic human congenital abnormalities. Dev. Biol. 120, 198-214. doi: 10.1016/0012-1606(87) 90118-7

Couly, G., and Le Douarin, N. M. (1988). The fate map of the cephalic neural primordium at the presomitic to the 3-somite stage in the avian embryo. Development 103(Suppl.), 101-113.

Crossley, P. H., Martinez, S., Ohkubo, Y., and Rubenstein, J. L. (2001). Coordinate expression of Fgf8, Otx2, Bmp4 and Shh in the rostral prosencephalon during development of the telencephalic and optic vesicles. Neuroscience 108, 183-206. doi: 10.1016/s0306-4522(01)00411-0

Drouin, J., Lamolet, B., Lamonerie, T., Lanctôt, C., and Tremblay, J. J. (1998). The PTX family of homeodomain transcription factors during pituitary developments. Mol. Cell. Endocrinol. 140, 31-36. doi: 10.1016/s03037207(98)00026-4

Dubois, P. M., and Elamraoui, A. (1995). Embryology of the pituitary gland. Trends Endocrinol. Metab. 6, 1-7. doi: 10.1016/1043-2760(94)00090-Q

Dutta, S., Dietrich, J. E., Aspöck, G., Burdine, R. D., Schier, A., Westerfield, M., et al. (2005). pitx3 defines an equivalence domain for lens and anterior pituitary placode. Development 132, 1579-1590. doi: 10.1242/dev.01723

Eagleson, G. W., and Dempewolf, R. D. (2002). The role of the anterior neural ridge and Fgf- 8 in early forebrain patterning and regionalization in Xenopus laevis. Comp. Biochem. Physiol. B Biochem. Mol. Biol. 132, 179-189. doi: 10.1016/s10964959(01)00521-8

Eagleson, G. W., Jenks, B. G., and Van Overbeeke, A. P. (1986). The pituitary adrenocorticotropes originate from neural ridge tissue in Xenopus laevis. $J$. Embryol. Exp. Morphol. 95, 1-14.

elAmraoui, A., and Dubois, P. M. (1993). Experimental evidence for the early commitment of the presumptive adenohypophysis. Neuroendocrinology 58, 609615. doi: 10.1159/000126599

Fernández-Garre, P., Rodríguez-Gallardo, L., Gallego-Díaz, V., Alvarez, I. S., and Puelles, L. (2002). Fate map of the chicken neural plate at stage 4. Development 129, 2807-2822.

Ferran, J. L., Ayad, A., Merchán, P., Morales-Delgado, N., Sánchez-Arrones, L., Alonso, A., et al. (in press). "Exploring brain genoarchitecture by single and double chromogenic in situ hybridization (ISH) and immunohistochemistry (IHC) in whole-mount embryos. Chapter 4," in In Situ Hybridization Methods. Series: Neuromethods (Vol. 99), ed G. Hauptmann.

García-Calero, E., Fernández-Garre, P., Martínez, S., and Puelles, L. (2008). Early mammillary pouch specification in the course of prechordal ventralization of the forebrain tegmentum. Dev. Biol. 320, 366-377. doi: 10.1016/j.ydbio.2008.05. 545

García-Castro, M. I., Vielmetter, E., and Bronner-Fraser, M. (2000). N-Cadherin, a cell adhesion molecule involved in establishment of embryonic left-right asymmetry. Science 288, 1047-1051. doi: 10.1126/science.288.5468.1047

Guner, B., Ozacar, A. T., Thomas, J. E., and Karlstrom, R. O. (2008). Graded hedgehog and fibroblast growth factor signaling independently regulate pituitary cell fates and help establish the pars distalis and pars intermedia of the zebrafish adenohypophysis. Endocrinology 149, 4435-4451. doi: 10.1210/en. 2008-0315

Hamburger, V., and Hamilton, H. L. (1951). A series of normal stages in the development of the chick embryo. J. Morphol. 88, 49-92. doi: 10.1002/jmor. 1050880104

Hatada, Y., and Stern, C. D. (1994). A fate map of the epiblast of the early chick embryo. Development 120, 2879-2889. 
Hermesz, E., Mackem, S., and Mahon, K. A. (1996). Rpx: a novel anterior-restricted homeobox gene progressively activated in the prechordal plate, anterior neural plate and Rathke's pouch of the mouse embryo. Development 122, $41-52$.

Herzog, W., Sonntag, C., Walderich, B., Odenthal, J., Maischein, H. M., and Hammerschmidt, M. (2004). Genetic analysis of adenohypophysis formation in zebrafish. Mol. Endocrinol. 18, 1185-1195. doi: 10.1210/me.2003-0376

Houart, C., Westerfield, M., and Wilson, S. W. (1998). A small population of anterior cells patterns the forebrain during zebrafish gastrulation. Nature 391, 788-792. doi: 10.1038/35853

Izpisúa-Belmonte, J. C., De Robertis, E. M., Storey, K. G., and Stern, C. D. (1993). The homeobox gene goosecoid and the origin of organizer cells in the early chick blastoderm. Cell 74, 645-659. doi: 10.1016/0092-8674(93)90512-o

Khudyakov, J., and Bronner-Fraser, M. (2009). Comprehensive spatiotemporal analysis of early chick neural crest network genes. Dev. Dyn. 238, 716-723. doi: 10.1002/dvdy.21881

Kimura, W., Yasugi, S., Stern, C. D., and Fukuda, K. (2006). Fate and plasticity of the endoderm in the early chick embryo. Dev. Biol. 289, 283-295. doi: 10.1016/j. ydbio.2005.09.009

Lanctôt, C., Lamolet, B., and Drouin, J. (1997). The bicoid-related homeoprotein Ptxl defines the most anterior domain of the embryo and differentiates posterior from anterior lateral mesoderm. Development 124, 2807-2817.

Lopez-Sanchez, C., Garcia-Masa, N., Gañan, C. M., and Garcia-Martinez, V. (2009). Movement and commitment of primitive streak precardiac cells during cardiogenesis. Int. J. Dev. Biol. 53, 1445-1455. doi: 10.1387/ijdb.072417cl

New, D. A. (1955). A new technique for the cultivation of the chick embryo in vitro. J. Embryol. Exp. Morphol. 3, 320-321.

Parkinson, N., Collins, M. M., Dufresne, L., and Ryan, A. K. (2010). Expression patterns of hormones, signaling molecules and transcription factors during adenohypophysis development in the chick embryo. Dev. Dyn. 239, 1197-1210. doi: $10.1002 /$ dvdy.22250

Puelles, L., Domenech-Ratto, G., and Martinez-de-la-Torre, M. (1987). Location of the rostral end of the longitudinal brain axis: review of an old topic in the light of marking experiments on the closing rostral neuropore. J. Morphol. 194, 163-171. doi: 10.1002/jmor.1051940205

Puelles, L., and Rubenstein, J. L. (2003). Forebrain gene expression domains and the evolving prosomeric model. Trends Neurosci. 26, 469-476. doi: 10.1016/s01662236(03)00234-0

Reyes, R., González, M., and Bello, A. R. (2008). Origin of adenohypophysial lobes and cells from Rathke's pouch in chicken (Gallus gallus) and Japanese quail (Coturniz coturniz japonica). Expression of calcium-binding proteins. Anat. Histol. Embryol. 37, 272-278. doi: 10.1111/j.1439-0264.2007.00840.x

Rizzoti, K., and Lovell-Badge, R. (2005). Early development of the pituitary gland: induction and shaping of Rathke's pouch. Rev. Endocr. Metab. Disord. 6, 161172. doi: 10.1007/s11154-005-3047-7

Romanoff, A. (1960). The Avian Embryo. Structural and Functional Development. New York: The Macmillan Co.

Sabado, V., Barraud, P., Baker, C. V., and Streit, A. (2012). Specification of GnRH-1 neurons by antagonistic FGF and retinoic acid signaling. Dev. Biol. 362, 254262. doi: 10.1016/j.ydbio.2011.12.016

Sanchez-Arrones, L., Ferrán, J. L., Rodráguez-Gallardo, L., and Puelles, L. (2009). Incipient forebrain boundaries traced by differential gene expression and fate mapping in the chick neural plate. Dev. Biol. 335, 43-65. doi: 10.1016/j.ydbio. 2009.08.012

Sanchez-Arrones, L., Stern, C. D., Bovolenta, P., and Puelles, L. (2012). Sharpening of the anterior neural border in the chick by rostral endoderm signalling. Development 139, 1034-1044. doi: 10.1242/dev.067934

Schweickert, A., Steinbeisser, H., and Blum, M. (2001). Differential gene expression of Xenopus Pitx1, Pitx2b and Pitx2c during cement gland, stomodeum and pituitary development. Mech. Dev. 107, 191-194. doi: 10.1016/s09254773(01)00461-0

Selleck, M. A., and Stern, C. D. (1991). Fate mapping and cell lineage analysis of Hensen's node in the chick embryo. Development 112, 615-626.

Sheng, H. Z., Moriyama, K., Yamashita, T., Li, H., Potter, S. S., Mahon, K. A., et al. (1997). Multistep control of pituitary organogenesis. Science 278, 1809-1812. doi: 10.1126/science.278.5344.1809

Sheng, H. Z., and Westphal, H. (1999). Early steps in pituitary organogenesis. Trends Genet. 15, 236-240. doi: 10.1016/s0168-9525(99)01742-4

Sjödal, M., and Gunhaga, L. (2008). Expression patterns of Shh, Ptc2, Raldh3, Pitx2, Isl1, Lim 3 and Pax6 in the developing chick hypophyseal placode and Rathke's pouch. Gene Expr. Patterns 8, 481-485. doi: 10.1016/j.gep.2008.06.007

Stalsberg, H., and DeHaan, R. L. (1968). Endodermal movements during foregut formation in the chick embryo. Dev. Biol. 18, 198-215. doi: 10.1016/00121606(68)90043-2

Stern, C. D., and Bachvarova, R. (1997). Early chick embryos in vitro. Int. J. Dev. Biol. 41, 379-387.

Streit, A. (2002). Extensive cell movements accompany formation of the otic placode. Dev. Biol. 249, 237-254. doi: 10.1006/dbio.2002.0739

Streit, A., and Stern, C. D. (2001). Combined whole-mount in situ hybridization and immunohistochemistry in avian embryos. Methods 23, 339-344. doi: 10. 1006/meth.2000.1146

Suh, H., Gage, P. J., Drouin, J., and Camper, S. A. (2002). Pitx2 is required at multiple stages of pituitary organogenesis: pituitary primordium formation and cell specification. Development 129, 329-337.

Takor, T. T., and Pearse, A. G. (1975). Neuroectodermal origin of avian hypothalamo-hypophyseal complex: the role of the ventral neural ridge. $J$. Embryol. Exp. Morphol. 34, 311-325.

Treier, M., Gleiberman, A. S., O'Connell, S. M., Szeto, D. P., McMahon, J. A., McMahon, A. P., et al. (1998). Multistep signaling requirements for pituitary organogenesis in vivo. Genes Dev. 12, 1691-1704. doi: 10.1101/gad.12.11. 1691

Whitlock, K. E., and Westerfield, M. (2000). The olfactory placodes of the zebrafish form by convergence of cellular fields at the edge of the neural plate. Development 127, 3645-3653.

Whitlock, K. E., Wolf, C. D., and Boyce, M. L. (2003). Gonadotropin-releasing hormone $(\mathrm{GnRH})$ cells arise from cranial neural crest and adenohypophyseal regions of the neural plate in the zebrafish, Danio rerio. Dev. Biol. 257, 140-152. doi: 10.1016/s0012-1606(03)00039-3

Withington, S., Beddington, R., and Cooke, J. (2001). Foregut endoderm is required at head process stages for anteriormost neural patterning in chick. Development $128,309-320$.

Conflict of Interest Statement: The authors declare that the research was conducted in the absence of any commercial or financial relationships that could be construed as a potential conflict of interest.

Received: 27 November 2014; paper pending published: 15 December 2014; accepted: 12 January 2015; published online: 17 February 2015.

Citation: Sánchez-Arrones L, Ferrán JL, Hidalgo-Sanchez M and Puelles L (2015) Origin and early development of the chicken adenohypophysis. Front. Neuroanat. 9:7. doi: 10.3389/fnana.2015.00007

This article was submitted to the journal Frontiers in Neuroanatomy.

Copyright (C) 2015 Sánchez-Arrones, Ferrán, Hidalgo-Sanchez and Puelles. This is an open-access article distributed under the terms of the Creative Commons Attribution License (CC BY). The use, distribution and reproduction in other forums is permitted, provided the original author(s) or licensor are credited and that the original publication in this journal is cited, in accordance with accepted academic practice. No use, distribution or reproduction is permitted which does not comply with these terms. 